\title{
TREINO E GENERALIZAÇÃO DE LEITURA CRÍTICA E CRIATIVA: UM ESTUDO EXPERIMENTAL COM UNIVERSITÁRIOS
}

\section{TRAINING AND A GENERALIZATION OF THE CRITICAL AND CREATIVE READING: EXPERIMENTAL STUDY WITH UNIVERSITY STUDENTS}

\author{
Carmen Lúcia Hussein* \\ Universidade de Taubaté
}

\begin{abstract}
RESUMO
O objetivo deste trabalho foi testar a eficiência de procedimentos de treino em leitura crítica e leitura criativa. Ainda foi o de verificar a generalização do treino de leitura crítica para a motivação, compreensão e leitura criativa. Também foi verificado a generalização do treino de leitura criativa para a motivação, compreensão leitura crítica. Os dados obtidos demonstraram a eficiência dos treinos oferecidos. Quanto à generalização, pode-se dizer que o grupo submetido ao treino de criticidade conduziu a produção de criatividade textual. Todavia, o procedimento de treino de criatividade textual não afetou o comportamento de criticidade textual. Finalmente, pode-se concluir que a variável modalidade de treino não controlou a produção dos comportamentos de compreensão e motivação de leitura.
\end{abstract}

Palavras-chave: Aprendizagem Verbal, Aprendizagem da Leitura, Leitura e Desenvolvimento.

\section{SUMMARY}

The objective of this work is to assess the efficiency of training procedures employed in critical and creative readings. Further, the generalization of the critical reading to the case of motivation, comprehension and creative reading. Similar discussion was made with regards to creative reading training. The results demonstrated the efficiency of offered training. It was observed that the E. G.I group develops the production of textual creativity. The procedure of the textual creativity training did not affect the textual criticality behaviour. Finally, one mar conclude that the training variable was not efficient in controlling the production of the comprehension and motivation behaviour-reading.

Key words: Verbal Learning, Reading Learning, Reading and Development.

(") Este trabalho foi subvencionado pelo CNPq enquanto pesquisadora do IPUSP. 


\section{INTRODUÇÃO}

O objetivo do presente estudo é fornecer alguma contribuição para o conhecimento de remediação de leitura com estudantes universitários, na medida em que DURAN (1981) SANTOS (1989) e WITTER (1997) constataram em nosso meio a inabilidade de universitários para compreender a informação lida. Além disso, encontra-se na literatura a carência de pesquisas sobre as variáveis que controlam o ensino da leitura crítica e criativa com universitários e os instrumentos de mensuração e a relação destes com outros comportamentos acadêmicos. Finalmente, pretende-se estudar algumas técnicas que sejam suficientemente simples para serem usadas na sala de aula pelo professor e que utilizem meiose recursos que estejam disponíveis em nosso meio.

$\mathrm{Na}$ literatura sobre o comportamento do professor e o processo de ensino-aprendizagem do comportamento textual crítico e criativo, um aspecto bastante enfatizado é o uso de questões pelo docente (WOLF, KING E HUCK, 1968). Outro aspecto sugerido para o ensino de leitura crítica e criativa é o uso de atividades que permitem a apresentação para uma audiência do trabalho realizado pelo leitor, assim como o levam a comparar e a contrastar diferentes pontos de vista (DeBOER, 1964; HARVISON, 1967 e BOYAN, 1972).

Nesse sentido, HUSSEIN (1982) usando alunos da $5^{\text {a }}$ série constatou que o uso pela professora de determinadas questões orais combinado com a audiência fornecida pelos colegas e professora da classe levou à produção de criticidade e criatividade textual nos grupos que receberam esse treino em relação a outros grupos que passaram por outras modalidades de treino.

O estudo acima parece apoiar o uso do modelo de análise funcional do comportamento verbal para o treino de leitura crítica e criativa, mostrando a relevância dos $\mathrm{s}^{\mathrm{D}}$ antecedentes (questões) e do reforçamento social (dos alunos e da professora) liberados pela audiência no desenvolvimento e manutenção desses comportamentos.

Através do uso de questões, com estudantes universitários, SAMPAIO (1983) submeteu os sujeitos a um treino de leitura criativa de relatos de pesquisa. A autora constatou que o procedimento utilizado foi eficiente no desenvolvimento desse comportamento e também houve generalização do treino de Criatividade para a Criticidade.

No presente trabalho, a leitura crítica é definida como a habilidade do estudante universitário em verificar se as informações contidas no texto estão baseadas em fatos ou em opiniões do autor, mantendo o nível de adequação ao contexto de leitura. Ainda, a Leitura Criativa é definida como aquela habilidade que vai além do texto, propondo base de relações com outros textos, e com a vida do próprio sujeito, bem como soluções e proposições diversas, quer em apoio ao autor quer dele se diferenciando em nível de oposição, porém mantendo o nível de adequação da resposta.

Apesar das habilidades mais complexas de leitura não enfatizadas pelos educadores, pode-se concluir que são escassas as pesquisas com universitários nessa área. Também, pode-se dizer que são necessários estudos que possam dar algum esclarecimento quanto ao treino dessas habilidades em sala de aula eque possam explicitar melhor o efeito do uso de questões e da ciência do desempenho sobre esses comportamentos nos universitários.

Dentro do referencial até aqui apresentado formularam-se como objetivos para a presente pesquisa: 1) verificar a eficiência de um procedimento de treino em leitura crítica para alunos universitários; 2) verificar a generalização do treino em leitura crítica para a motivação, compreensão e leitura criativa; 3) verificar a eficiência de um procedimento de treino em leitura criativa para alunos universitários; 4) verificar a generalização do treino em leitura criativa para a motivação,compreensão e leitura crítica. 


\section{Método}

\section{Sujeitos}

O número de sujeitos deste trabalho foi de 20 alunos determinado a partir da população constituinte de um Curso extracurricular "Treino de Habilidades Gerais de Leitura" oferecido aos alunos do 10 ano de Psicologia de uma universidade municipal do Estado de São Paulo.

Foram utilizados dois grupos a partir desse curso: Grupo Experimental I (G.E.I) e o Grupo Experimental II. (G. E.II), sendo que cada um deles era constituído de dez sujeitos (nove do sexo feminino e um do sexo masculino). A idade média dos sujeitos era de 20 anos, sendo que o G.E.I tinha a idade média de 21 anos e o G.E.Il de 19 anos. Todos os alunos eram solteiros, $65 \%$ moravam com a família e $95 \%$ não trabalhavam.

\section{Material}

Foi adaptado pela autora do presente estudo para alunos universitários o questionário de Caracterização do Comportamento de Ler (Q.C.C.L.) elaborado e usado por VIESSI (1979) que constatou a sua adequação quanto: a) à habilidade de compreensão dos escolares de 5 a série do I grau; b) o objetivo de discriminar os leitor relutantes dos motivados para com o ato de ler e c) à finalidade de detectar os temas preferidos em leitura por esses sujeitos.

Como uma medida de compreensão de leitura foi usada a técnica de cloze (URBAN, 1981, KOPKE FILHO, 1981 e WITTER, 1997). Foram estabelecidas 40 lacunas, seguindo-se o modelo padrão. A primeira e última oração não sofreram apagamentos. Utilizou-se um texto desconhecido pelos alunos.

O critério para a seleção de textos para usar nos testes de Criticidade e Criatividade foi o de utilizar dois trechos de uma mesma autora, cujo discurso versava sobre aspectos diferen- tes do mesmo assunto, que continham quase a mesma quantidade de páginas (4 a 5 folhas). Estes textos tinham uma seqüência lógica de começo, meio e fim para serem utilizados no Pré e Pós-Teste.

O teste de Criticidade foi constituído de questões que foram as seguintes: 1) $O$ autor define o problema justificando-se em fatos ou em opiniões? Porquê?, 2) A temática afirmada pelo autor quanto às implicações educacionais está baseada em fatos ou em opiniões? Por quê?, 3) A argumentação do autor quanto às implicações teóricas está justificada em fatos ou em opiniões? Por quê? e 4) As premissas e conclusões do problema estão baseadas em fatos ou em opiniões? Por quê? Os tipos de questões do teste de Criatividade foram: 1) Que outros problemas poderiam ser levantados? ,2) Que outras implicações educacionais poderiam ser apontadas?, 3) Que outras implicações teóricas poderiam ser levantadas? e 4) Que outras conclusões poderiam ser formuladas?

Os textos de leitura para o treino foram sobre a aprendizagem verbal, conforme o interesse demonstrado pelos alunos por temas de Psicologia, que foram obtidos através do Q.C.C.L.. Outro critério foi que os textos aumentassem gradativamente o número de páginas. As folhas de respostas dos alunos, após o cabeçalho, quase todas variaram de uma até quatro questões, semelhantes às usadas no Teste de Criticidade e Criatividade.

\section{Procedimento}

Foram aplicados em cada aula no Pré e Pós-Teste para os dois grupos experimentais o Questionário de Caracterização do Comportamento de Ler, o Texto Cloze, o Teste de Criticidade e o de Criatividade.

O procedimento constou de oito sessões de treino. A duração de cada sessão foi de aproximadamente uma hora aula. O planejamento foi feito de modo a viabilizar a 
concretização da coleta de dados de pesquisa dentro do espaço de tempo disponível em um semestre letivo.

O G.E.I recebeu o treino de Criticidade e o G.E.ll o treino de Criatividade.

A aplicadora ou a experimentadora seguia os itens das folhas de instruções para o Treino de Criticidade e para o Treino de Criatividade.

$O$ treino iniciou-se simultaneamente para ambos os Grupos Experimentais e foi constituído de duas fases: Fase 1 e Fase 2. Para não alterar a rotina escolar, optou-se, neste trabaIho, pela não separação dos grupos, sendo que cada grupo recebia instruções impressas adequadas às atividades a serem desenvolvidas para cada um deles. Entretanto, a condução da Fase 1 foi realizada sempre na mesma sala. As sessões da Fase 2 foram realizadas, na maioria das vezes nesta sala e, às vezes numa sala ao lado, para os alunos que estavam atrasados em relação ao exercício preparado para aquele dia, sendo que, portanto, concomitantemente, a aplicadora ou a experimentadora dirigiam 0 Exercício fixado ou a atividade em atraso ao programa proposto.

A Fase 1 (1a aula) constou, para o grupo que recebeu o Treino de Criticidade da leitura de cada aluno, de um texto programado "Questões: Importância-distinção entre fato e opinião" (CHEVES, 1973), tendo como objetivos levar os alunos a indicarem a relevânciadas questões e a distinguir o que é fato e o que é opinião no material lido. Considerou-se a necessidade de um texto preliminar na medida em que se constatou no estudo de HUSSEIN (1982) que os sujeitos apresentaram um grande número de respostas inadequadas durante e após o Treino de Criticidade Textual, apesar do progresso em relação ao Pré, indicando possivelmente a necessidade de pré-requisitos. Também isso justifica a inclusão,na Fase 2 (7 aulas), da Folha de Instruções para o Treino de Criticidade que o estudante de Psicologia sempre recebia para ler antes de realizar cada sessão de treino de leitura crítica e era mantida durante toda a sessão. Essa folha de instruções começa por considerações sobre a importância da atitude de curiosidade e de crítica na formação do psicólogo. Depois ela apresenta em primeiro lugar a definição de "Fato Científico em Psicologia" seguido de vários exemplos extraídos de diversos textos. Em segundo lugar, a Folha define "Opinião" e mostra vários exemplos de autores que indicam este comportamento. Ainda, essa instrução conceitua "inferência" seguido de alguns trechos para exemplificar essa definição. Finalmente, ela apresenta no final a síntese desses três conceitos e indica para o leitor que o treino de leitura crítica proposto tem por objetivo desenvolver a habilidade de distinguir "Fatos" de "Opiniões".

A Fase 2, a partir da constatação da dificuldade dos alunos de responderem às quatro questões no Teste de Criticidade, utilizou o procedimento de modelagem. Assim, os exercícios 1 e 2 solicitavam do aluno grifar as afirmações mais importantes do texto lido com linha cheia (-) quando fossem fatos e com linha pontilhada (-----) quando fossem opiniões. Quanto aos Exercícios 3, 4, 5 e 6 solicitavam do leitor responder apenas uma questão, isto é, a primeira, a segunda, a terceira e a quarta questão usadas no Teste de Criticidade, respectivamente. No exercício 7 foram apresentadas todas as quatro questões desse instrumento após a leitura do texto.

Após a obtenção das respostas a aplicadora ou a experimentadora recolhia o material e agradecia o trabalho do aluno.

Após cada treino a experimentadora verificava as folhas de resposta e as devolvia para os sujeitos conhecerem a avaliação de seu desempenho, antes de passarem para nova sessão de treino.

O sujeito que faltasse à sessão proposta para a aula do dia era dada a oportunidade de passar por esse treino na aula seguinte e também realizar o exercício do programa. Porém, sempre o exercício realizado era verificado antes pela experimentadora para que o sujeito pudesse caminhar para o passo seguinte.

A Fase 1 (1 ${ }^{a}$ aula) constou, para o Grupo que recebeu o treino de Criatividade, de leitura de um trecho da Tese de Doutoramento de 
HUSSEIN (1982, p. 43 a 50), que versava sobre o conceito, o ensino e a aprendizagem de Leitura Criativa. Também aqui levou-se em conta a necessidade de um texto preliminar para o Treino de Criatividade pela possível necessidade de pré-requisitos constatados por HUSSEIN (1982).

Foi incluído, também, na Fase 2 (7 aulas) a Folha de Instruções para o Treino de Criatividade que o universitário sempre recebia para ler antes de passar pelo treino de leitura criativa e que permanecia durante toda a sessão. Essa folha foi adaptada da revisão feita por HUSSEIN (1982) sobre o conceito de leitura criativa.

A Fase 2, pelo mesmo motivo indicado anteriormente, também usou o procedimento de modelagem, sendo que os Exercícios 1 e 2 solicitavam do aluno grifar as afirmações mais importantes do texto; Os exercícios seguintes diferiram dos usados no Treino de Criticidade, pelo tipo de questões, que neste caso eram as mesmas usadas no Teste de Criatividade.

Os passos seguintes eram iguais aos de Treino de Criticidade.

\section{RESULTADOS}

Quanto aos critérios utilizados nos testes aplicados foram usados no Q.C.C.L. os mes- mos usados por VIESSI (1979). Em relação ao Teste de Cloze foi considerado como resposta certa aquela que correspondesse exatamente ao vocábulo omitido do texto (TAYLOR, 1953). O critério geral, portanto, foi considerar a freqüência dos acertos, erros e respostas em branco emitidas pelos sujeitos. Finalmente em relação as categorias e o estudo de fidedignidade na avaliação dos Testes de Criticidade e Criatividade Textual encontram-se descritos no trabalho de HUSSEIN (1985).

Para a comparação inter-grupos os dados foram submetidos ao teste U de Mann e Whitney (SIEGEL, 1956) e para a comparação intragrupos ao teste de Wilcoxon (SIEGEL, 1956), usando o nível de significância de 0.05 .

O primeiro instrumento é um teste não paramétrico indicado para quando não se dispõe de informação sobre a curva de distribuição do comportamento focalizado. A hipótese nula foi a de igualdade entre os grupos (Ho: G.E.I=G.E.II)a hipótese alternativa a de diferença entre os dois grupos $\left(\mathbf{H}_{1}:\right.$ G.E.I $\neq$ G.E.II), sendo que o teste foi bicaudal, dado que na literatura específica não há dados que permitam supor a direção da diferença.

Os resultados encontram-se descritos em relação a cada instrumento usado no presente estudo e encontram-se expressos na Tabela I.

Tabela 1 - Comparação entre os G.E.I e o G.E.II, quanto ao desempenho nos instrumentos usados, no Pré e Pós-Teste $\left(N_{1}\right.$ e $\left.N_{2}=10\right)\left(H_{0}\right.$ : G.E.I=G.E.II e Ha: G.E.I $\left.\neq G . E . I I\right)$.

\begin{tabular}{|c|c|c|c|c|c|c|}
\hline \multirow{2}{*}{ INSTRUMENTOS } & \multicolumn{2}{|c|}{ PRÉ } & \multirow{2}{*}{$\mathrm{H}_{0}$} & \multicolumn{2}{|c|}{ Pós } & \multirow{2}{*}{$\mathrm{H}_{\mathrm{o}}$} \\
\hline & $\mathrm{U}_{0}$ & $\mathrm{U}_{\mathrm{c}}$ & & $\mathrm{U}_{\mathrm{o}}$ & $\mathrm{U}_{\mathrm{c}}$ & \\
\hline Teste de Cloze - Acertos & 48 & 23 & não rejeitada & 37 & 23 & năo rejeitada \\
\hline Teste de Cloze - Erros & 33,5 & 23 & não rejeitada & 45,5 & 23 & não rejeitada \\
\hline Teste de Cloze - Em branco & 35,0 & 23 & não rejeitada & 43,5 & 23 & mão rejeitada \\
\hline Teste de Criticidade & 45,0 & 23 & não rejeitada & 7 & 23 & rejeitada \\
\hline Teste de Criatividade & 46,0 & 23 & năo rejeitada & 46 & 23 & não rejeitada \\
\hline Q.C.C.L & 48,0 & 23 & não rejeitada & 44,5 & 23 & năo rejeitada \\
\hline
\end{tabular}


Conforme pode ser verificado por esta tabela, a única diferença significante que se apresentou foi em relação ao Teste de Criticidade na fase de Pós-Teste, em que a hipótese nula foi rejeitada. Os dados também indicam que para as comparações restantes a hipótese nula não foi rejeitada.

A comparação Intra-Grupos teve por objetivo verificar o efeito da modalidade de treino sobre o desempenho dos estudantes de psicologia nos instrumentos usados. Este é um instrumento não paramétrico, sendo indicada a sua aplicação para quando se lida com amostras dependentes entre si, para as quais não se dispõe de dados suficientes para pressupor uma distribuição normal e não se leva em consideração a média, mas sim o desempenho de cada sujeito no grupo.

Levantou-se por hipótese de nulidade, que pré = pós e por hipótese alternativa estabeleceu-se que, como os sujeitos foram submetidos a alguma modalidade de treino, teriam desempenho superior no pós-teste quando comparado ao pré, ou seja Ha: Pré < Pós, sendo estabelecida uma base unidirecional.

Para verificar a eficiência do treino recebido pelos grupos experimentais realizaram-se comparações entre o Pré e o Pós, que encontram-se expressas na Tabela II.

Tabela 2 - Comparação Intra-Grupos nos vários instrumentos no Pré e Pós (nível de significância de 0,05 ).

\begin{tabular}{llrrrr}
\hline \multirow{2}{*}{ INSTRUMENTO } & FASE & \multicolumn{2}{c}{ PRÉ X Pós } & \\
\cline { 2 - 6 } & GRUPO & N & TC & To & $\begin{array}{c}\text { Ho }=\text { Pré }=\text { Pós } \\
\text { H }_{1}=\text { Pré }<\text { Pós }\end{array}$ \\
\hline Cloze-Acerto & G.E.I & 8 & 8 & 14 & $\begin{array}{c}\text { não rejeitada } \\
\text { rejeitada }\end{array}$ \\
\hline Cloze-Erro & G.E.II & 10 & 16 & 8,5 & não rejeitada \\
& G.E.I & 9 & 12 & 21,5 & rejeitada \\
\hline Cloze em Branco & G.E.II & 10 & 16 & 5,5 & não rejeitada \\
& G.E.I & 9 & 12 & 21,5 & rejeitada \\
\hline Teste de Criticidade & G.E.II & 8 & 8 & 0 & rejeitada \\
\hline
\end{tabular}

Teste de CriatividadAssim, de acordo com a Tabela II encon-12 Tešte de Criticidadełę,apara as comparações trou-se quanto aoGTeste de Clozéque o G.E.I16 restantes não hơuịẹaesta indicação.

Q.C.C.L obteve a hipótese 22,5 as categorias e G.G.E.II apresentou rejeição16 17,5 não rejeitada dessa hipótese para todas as comparações.

Também, foi encontrado para o Teste de Criticidade e Criatividade que apenas o G.E.II demonstrou que Ho não foi rejeitada para o

Em primeiro lugar, procurou-se atender, na medida do possível, a seqüência de apresentação dos objetivos. O primeiro objetivo 
refere-se à verificação da eficiência de um procedimento de treino em leitura crítica e leitura criativa para alunos universitários. A seguir, foi verificada a generalização desses treinos para outros comportamentos.

Foram considerados, primeiramente, os dados referentes às comparações inter-grupos e, depois, as comparações intra-grupos. Desse modo, para se verificar o atendimento dos objetivos focalizaram-se as comparações entre o Pré e Pós.

Quanto ao presente estudo cabem algumas considerações de caráter metodológico. A opção por trabalhar numa situação mais complexa tem a vantagem de tornar mais rápida a aplicação na situação real, sem ocorrer o risco dos revezes da transposição do laboratório para a sala de aula, se bem que exija um maior número de réplicas, que dêem maior segurança no detectar variáveis relevantes. Assim, no presente estudo optou-se pela exclusão de um eventual grupo de controle, o que conduziu a opção por um delineamento de pesquisa que permitisse a comparação de grupos experimentais entre si, de modo que, cada um dos grupos recebeu uma modalidade de treino, respectivamente. Pode-se notar, conforme o tratamento inter-grupos, que não houve diferenças significantes entre os grupos no Pré-Teste, face aos instrumentos usados.

Focalizando a comparação inter-grupos e intra-grupos, os dados mostraram que o treino de criticidade parece ter sido o mais eficiente no desenvolvimento desse comportamento. Entretanto, os dados inter-grupos mostraram que não houve diferenças significantes entre os grupos quanto à produção de criatividade textual e os resultados intra-grupos apresentaram que ambos os grupos indicaram melhoria deste comportamento.

Assim, os dados encontrados confirmam as pesquisas experimentais que tratam do efeito de alguns programas sobre a aprendizagem de criticidade textual, como os de SHEARIN (1976) e PACHTMAN (1977), com os estudan- tes universitários, que demonstraram que 0 treino oferecido de leitura crítica produziu desenvolvimento na criticidade textual. Ainda, focalizando a leitura crítica de relatos de pesquisa por SAMPAIO (1983) a qual usou com universitários de João Pessoa a Escala de Avaliação de Artigos relatando pesquisa (ARRR) de WARD, HALL e SCHRAMM (1975), os dados mostraram que o procedimento foi eficiente para a produção desse comportamento. Todavia, esses estudos usaram definições de leitura crítica diferente das aqui usadas.

Também, os resultados comprovaram os obtidos por HUSSEIN (1982), com escolares de 5 a série e os de SAMPAIO (1983), utilizando estudantes universitários, que verificaram a eficiência do procedimento de treino de leitura criativa no desenvolvimento de criatividade textual.

Entretanto, quanto ao desempenho nas categorias de criticidade textual, pode-se observar a coerência dos dados brutos específicos não aglutinados com os tratamentos inter $\mathrm{e}$ intra-grupos, quanto à tendência de indicar o melhor desempenho neste comportamento no grupo que foi submetido ao treino de criticidade. Também, é interessante notar que, apesar deste grupo apresentar uma tendência de diminuição das respostas inadequadas após o treino, assim mesmo, a ocorrência de comportamento inadequados foi alta e houve aumento da justificativa elaborada em relação ao outro grupo. Porém, quanto às categorias de criatividade textual, ambos os grupos apresentaram diminuição de respostas inadequada se um aumento de fluência e flexibilidade.

Esses dados, e considerando a definição aqui adotada sobre leitura crítica, como a habilidade do estudante universitário em verificar se as informações mantidas no texto estão baseadas em fatos ou em opiniões do autor, mantendo o nível de adequação ao contexto de leitura, parecem sugerir que os universitários utilizados neste estudo não estão acostumados a realizar a análise do texto em fatos ou em opiniões. 
Estes resultados parecem comprovar que as condições sócio-educacionais de escolas e famílias em nosso meio, certamente enfatizam o uso de reprodução, havendo pouca oportunidade de os alunos aprenderem esta habilidade. Também, confirmam certamente as conclusões de HUSSEIN (1982, p. 176) "de que esta habilidade seja iniciada desde a escola elementar e de colocar o ensino de leitura crítica como parte do programa normal de leitura nas escolas, além dos textos utilizados nas classes deverem incluir o ensino dessa habilidade". Todavia, cabe aqui propor além de pesquisa de réplica com uma duração de treino maior, estudos que utilizem outras habilidades de leitura crítica.

Assim, esses resultados parecem comprovar os obtidos por HUSSEIN (1982) que constatou que o uso pela professora de determinadas questões orais combinado com a audiência fornecida pelos colegas e professores levou à produção de criticidade e criatividade textual nos grupos que receberam estas modalidades de treino.

O presente estudo parece comprovar o uso do modelo de análise funcional do comportamento verbal para o treino desses comportamentos, demonstrando a importância do uso de questões para a emissão inicial destas respostas e do reforçamento social liberado pela audiência no desenvolvimento e manutenção da criticidade e criatividade textual.

Desse modo, considerando o aspecto conceitual, seriam relevantes pesquisas que demonstrassem qual o poder controlados mais eficiente: antecedentes ou conseqüentes? São os primeiros suficientes? Pode-se dispensar o controle das questões, ficando apenas com o texto e o reforçamento da audiência. Todavia, o presente trabalho com estudantes de $1^{\circ}$ ano de Psicologia apresentou alguma indicação da maior relevância da audiência do que o uso de questões como estímulos discriminativos, na medida em que o repertório do aluno solicitou outros tipos de SD (folhas de instruções e forma alternada de distribuição do texto). Além disso, essa mesma autora, no estudo com escolares de 5a série, constatou que apesar da melhoria desses comportamento após o treino, assim mesmo a ocorrência de comportamento inadequados foi alta, o que indica a possibilidade de utilização de outros SD e, possivelmente, a força da variável audiência e, certamente a necessidade de outros estudos a respeito desse problema. Desse modo, os dados parecem sugerir que o conhecimento pelo leitor do seu desempenho é uma variável que determina o desenvolvimento da criticidade e criatividade textual (HOFFMAN, 1979; WIMBEY e colaboradores, 1980 e MEMORY e MOORE, 1981).

Assim, estes dados confirmam as proposições teóricas de HOFFMAN, 1979 e MEMORY e MOORE, 1981 que sugerem a importância da audiência para conduzir a comparação e ao contraste de diferentes pontos de vista apresentados pelo texto.

Desse modo, ao se considerar a Universidade como agência formadora de pessoas que têm mais probabilidade de intervir na sociedade, torna-se necessário a realização de mais pesquisas sobre criticidade e criatividade, pois esses futuros profissionais deveriam possuir essas habilidades na área da ciência a que se dedicam (Labuda, 1988 e Witter, 1997).

Ainda, a criatividade e a criticidade são características relevantes do ser humano, para que este se torne um cidadão apto a agir no contexto social e a participar efetivamente do meio em que vive. A Universidade deve fornecer, aos docentes e alunos, condições para que a crítica construtiva e a criatividade enriquecedora da cultura e da própria vida possam se desenvolver sem restrições descabidas. Em um terreno ainda pouco pesquisado, não se pretendeu mais do que trazer alguma contribuição que pudesse instrumentar o professor universitário, na sua prática diária, criando condições objetivas para o desenvolvimento desses comportamentos nos seus alunos. 
Além da demonstração da eficiência dos treinos oferecidos é preciso verificar a potencialidade de generalização dessas modalidades de treino para outros comportamentos. Assim, quanto à verificação da generalização dos treinos para a criticidade e criatividade textual, pode-se depreender que a modalidade de treino de criticidade conduziu à produção de criatividade textual. Todavia, o procedimento de treino de criatividade textual não controlou o comportamento de criticidade textual.

Esses dados parecem, não comprovar os encontrados por HUSSEIN (1982), com escolares de 5 a série que o treino ( 6 horas) de criticidade e criatividade não levouà generalização desses comportamentos, respectivamente de um para outro. Também, os resultados não confirmam os de SAMPAIO (1983), com universitários (10 horas de treino) que encontrou evidências da generalização dos comportamentos de leitura crítica para leitura criativa e vice-versa.

Essa discrepância poderia ser devido ao número de horas de sessão, sendo que se pode concluir que, possivelmente, o aumento do número de sessões pudesse conduzir a uma melhoria na generalização desses comportamentos. Outra alternativa é que as definições de leitura crítica variaram, o que talvez tenha conduzido a diferenças nos resultados desses estudos. Todavia, seriam interessantes pesquisas posteriores a respeito dessa questão.

Outra explicação possível para os resultados encontrados, de que o grupo submetido ao treino de criticidade textual apresentou melhor generalização do que o grupo que recebeu criatividade, é que o leitor deve adquirir a criticidade textual antes de passar pelo treino de criatividade e que, ao hierarquizar a leitura pode-se dispor a leitura criativa em um nível mais alto do que a leitura crítica, o que parece corroborar as proposições teóricas de BARBE, 1976 e PERAHIA, 1979.

Assim, pode-se afirmar que os resultados do presente trabalho confirmam a ênfase dada por todos os especialistas naárea, behavioristas ou cognitivistas, que para se dispor de um bom leitor há necessidade de que o mesmo atinja o nível de leitura crítica. Assim, para PIAGET (apud STAUFFER, 1969), uma das metas de educação é formar pessoas que possam ser críticas, que submetam à análise determinado conhecimento e não aceitem tudo que lhe é oferecido.

Também, no presente estudo foram analisados o efeito da generalização dos treinos oferecidos para a compreensão e motivação para a leitura.

A comparação inter-grupos não evidenciou diferenças entre os grupos nestas habilidades tanto para o Pré como para o Pós-Teste. A comparação intra-grupos apenas demonstrou que o grupo submetido ao treino de criatividade apresentou melhor resultado no Pós-Teste, sendo que para as comparações restantes o desempenho foi o mesmo para as duas situações de teste.

Estes dados não apoiam os obtidos por BOODT (1984) usando crianças escolares, que evidenciou que as habilidades de compreensão de leitura parecem ser desenvolvidas com a instrução de leitura crítica. Também os resultados do presente trabalho não apoiam os encontrados por HUSSEIN (1982) com escolares da 5 a série, em que se constatou que o desenvolvimento da compreensão parece ter sido independente da variável experimental usada, no caso, a instrução recebida (leitura crítica, leitura criativa e reprodução de textos). Assim, esses dados sugerem que essa variável não foi relevante em termos de controlar a produção desse comportamento. Certamente, o material de leitura usado tenha sido a variável importante, que viabilizou o desenvolvimento da compreensão, na medida em que os cuidados tomados neste trabalho parecem ter sido eficientes quanto ao atendimento de interesse e no nível de compreensão dos sujeitos.

Porém, o presente trabalho com universitários parece demonstrar certamente a necessidade de estudos posteriores sobre a influên- 
cia da compreensão sobre o desenvolvimento de leitura crítica, sugerindo possivelmente critérios mais precisos em relação à motivação e ao nível de compreensão do estudante em nível superior, na medida em que os empregados talvez não tenham sido suficientes. Assim novos critérios poderiam ser usados para a hierarquização dos textos mais simples ao mais complexo. Talvez a seleção de textos não tenha sido suficientemente adequada aos sujeitos do presente estudo para desenvolver a compreensão e o nível de motivação (TOVEY, 1967; HUSSEIN, 1982).

Os dados do estudo ora relatados confirmam os encontrados por SHEARIN (1976), trabalhando com 52 universitários, que demonstrou que as habilidades de leitura crítica tinham tido algum progresso e que o programa foi eficiente para desenvolver criticidade mas não compreensão, conforme foi medido através de um teste padronizado. Porém, este programa enfatizou habilidades diferentes da aqui usada, como a de questionar o material escrito, de testar a fidedignidade das informações e de detectar a influência da propaganda no texto.

Entretanto, no presente estudo, os sujeitos apresentaram uma baixa motivação no PréTeste para a leitura, o que sugere que os sujeitos deste estudo parecem ser leitores relutantes, que podem ser definidos como um grupo de estudantes que são particularmente bons leitores e, apenas, não se interessam pela leitura, preferindo atividades que não envolvam o ato de ler. Segundo VIESSI (1979), a relutância se instala em câmara lenta ao longo de todo o processo educacional e, que de um modo geral, as causas estão relacionadas às condições sócio-educacionais anteriores que foram deficientes em termos de seu repertório de leitura.

Além disso, este trabalho evidenciou que a variável experimental (modalidade de treino) não controlou a motivação para a leitura. Assim não era esperado que um treino com duração de 8 horas-aula fosse suficiente para levar o aluno a modificar o seu nível de motivação para a leitura,o que sugere a proposição de pesquisas de réplica com uma duração maior de treino.

Assim, esses dados parecem apoiar as proposições de LAMB e ARNOLD, 1980; STRICKLER e ELTER, 1980; LAFFEY e MORGAN, 1980,que a influência das variáveis relacionadas àcomplexidade do comportamento de ler do estudante em nível superior é pouco conhecida, quanto ao seu desenvolvimento e manutenção, sendo que é possível que o potencial de influenciadas variáveis psicológicas (no caso, sendo considerada principalmente a motivação para a leitura) e, das variáveis sociológicas, seja mais relevante em relação à outras variáveis. Todavia, somente várias pesquisas poderão analisar a força de influência de cada um desses conjuntos de variáveis.

Segundo DURAN (1981), a revisão da literatura estrangeira aponta que é bastante evidenciado o interesse pelo ensino de leitura nesse nível. Porém, HAYES e DIEHL (1982) afirmam que a maior parte das instruções de habilidade de compreensão em universitários não se baseia em fundamentos da ciência psicológica e também eles apontam a dificuldade desses programas de conduzir à generalização do treino oferecido para a situação escolar, na medida em que eles são mais oferecidos como atividades extracurriculares do que em sala de aula. Portanto, seriam interessantes estudos quefocalizassem o efeito do método remediativo da compreensão sobre a generalização para outros comportamentos bem como para a situação acadêmica.

Também os resultados do presente estudo parecem demonstrar a indicação de que o repertório do aluno universitário apresenta dificuldades para a compreensão de textos, sugerindo, portanto, que o meio universitário, atualmente, tem recebido estudantes com limitações em sua formação anterior (DURAN, 1981; EGYPTO, 1983 e WITTER, 1997) e demonstrando a necessidade de pesquisas posteriores em relação a esta questão. 
Nesse sentido, PLEVINK (1981) afirma que a leitura deveria ser a preocupação mais importante na Universidade. Assim, atualmente a quantidade de informação disponível ao estudante universitário é imensa, o que conduz o leitor a dispender grande parte do seu tempo disponível localizando textos diversificados e apresentando a leitura de reprodução, sendo que o período de pensamento ativo e criativo no processo de leitura é relativamente pequeno.

Portanto, pode-se concluir pela necessidade de estudos de réplica e também que tenham por objetivo verificar os pré-requisitos para comportamentos de criatividade e criticidade textual. Assim sendo, poderiam ser testadas outras seqüências importantes para alcançar um nível ótimo dos comportamentos aqui tratados. Também, seriam necessárias pesquisas posteriores para responder mais seguramente se a compreensão de texto é ou não um dos pré-requisitos imprescindíveis para começar o treino de desenvolvimento destas respostas, ou se esse treino pode ter início começando do nível em que estive ro leitor, sem maiores preocupações com a compreensão.

\section{REFERÊNCIAS BIBLIOGRÁFICAS}

BARBE, W.B. (1975). Ingredients of a creative reading program. In: M. LABUDA. Creative reading for gifted learners a design for excellence. I.R.A., New York, Delaware.

BOODT, G.M. (1984). Critical listeners become critical readers in remedial reading class. The Reading Teacher, vol. 37, (no 4), 390-394.

CHEVES, D.A.P. (1973). An experiment in developing the ability to make inferences and to ask question wich require inference in sisth grade students. University of Missouri, Kansas City.

DeBOER, J. (1964). Teaching Critical Reading. The Elementary English Review, 23: 251-4.
DURAN, A.P. (1981) Padrões da Comunicação Oral e Compreensão da Comunicação Escrita na Universidade: Estudo no Nordeste. Tese de Doutoramento apresentada ao IPUSP, São Paulo.

HARVISON, A.R. (1967). Critical reading for elementary pupils. The Reading Teacher, 21: 244-7, 1967.

HAYES, \& DIEHL,W. (1982). What research on prose comprehension suggests for college skills instruction. Journal of Reading, 25 (7).

HOFFMAN, J.V.(1979). The intre-act procedure for critical reading. Journal of Reading, vol. 22 (7), 605-608.

HUSSEIN, C.L. (1982). Leitura Crítica e Criativa: Teste de Procedimentos de Treino e Generalização - um estudo com escolares da 5 a série. Tese de Doutoramento apresentada ao IPUSP.

HUSSEIN, C.L. (1985). Relatório no 3 de atividades do projeto "Teste de procedimentos de treino e generalização de Leitura Crítica e Criativa - um estudo experimental com universitários". Apresentado ao CNPq.

KOPKE FILHO, H. (1981). Criatividade em Redações e Inteligibilidade de Textos: um estudo quase experimental com alunos da $5^{a}$ série usando a técnica de Cloze. Tese de Mestrado apresentada a FFLCH da USP, São Paulo.

LABUDA, M. (1988). Creative reading forgifted learners. New York Delaware, International Reading Association.

LAFFEY, J.L. \& MORGAN, R. (1980). Sociological Bases. In: P. Lambe R. Arnold. Teaching Reading Foundation and Strategies. Belmont, California, Wadsworth Publ. Co.

LAMB, P. \& ARNOLD, R. (1980). Teaching Reading: Foundations and Strategies. Belmont, California, Wadsworth Publ. Co. 
MEMORY, M.D. \& MOORE, D.M. (1981). Selecting sources in library research: An activity in Skimming and critical reading. Journal of Reading, vol. 24 (6), 469-474.

PACHTMAN, A.B. (1977). The effects of a reading and language arts program on the critical reading of the first year law student. Dis. Abs. Int., vol. 38 (5-A), 2431-2432.

PERAHIA, P.J. (1976).Critical Reading Patterns of College, students majoring in Economics at Psychology. Hofstra University.

PLEVNIK, D. (1981). Reading - The most important concern for a University. Journal of Reading, 24 (7): 568-569.

SAMPAIO, S.T. Teste de procedimentos para treino em Leitura Crítica e Criativa: um estudo experimental com universitários. Tese apresentada na Faculdade de Educação da Universidade Federal da Paraíba.

SANTOS, A.A.A. (1989). Leitura entre universitários: diagnóstico e remediação. Tese de Doutoramento apresentada ao IPUSP, São Paulo.
SHEARIN, C.W. (1976). An evaluation of a program to teach critical reading skills to adult volunteers. Dis. Abs. Int., vol. 37 (3-A) 1355.

STAUFFER R.G. (1969). Directing reading maturity as a cognitive process. N.Y.; Harper e Row, cap. 10 e 11.

SIEGEL, S. (1956).Non parametric statistics for the behaviouralsciences. N. York, McGrawHill Book Co.

STRICKLER, D. \& ELLER, W. (1980). Atitudes and Interests. In: P. LAMB e R. ARNOLD. Teaching Reading:Foundationsand Strategies. Belmont, California, Wadsworth Publ. Co.

VIESSI, V.R (1979). Sistema contratual para leitores relutantes: um estudo com escolares

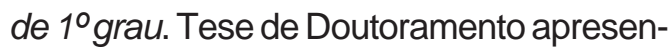
tada ao IPUSP, São Paulo.

WITTER, G.P. (1997). Psicologia: Leitura e Universidade. Editora Alínea, Campinas, SP.

WOLF, W., KING, M.L \& HUCK, C.S. (1968). Teaching critical reading to elementaryschool children. Reading Research Ouartely, vol. III, 4, 435-498. 